\title{
AN ENVIRONMENT FOR COLLECTIVE PERCEPTION BASED ON FUZZY AND SEMANTIC APPROACHES
}

\author{
Giuseppe D’Aniello ${ }^{1}$, Matteo Gaeta ${ }^{1}$, Francesca Loia ${ }^{2}$, Marek Reformat ${ }^{3}$, Daniele Toti ${ }^{4, *}$ \\ ${ }^{1}$ Department of Information and Electrical Engineering and Applied Mathematics, \\ University of Salerno, Fisciano, Italy \\ ${ }^{2}$ Department of Management, \\ Sapienza, University of Roma, Rome, Italy \\ ${ }^{3}$ Department of Electrical and Computer Engineering, \\ University of Alberta, Edmonton, Alberta, Canada \\ ${ }^{4}$ Department of Sciences, \\ Roma Tre University, Rome, Italy
}

Submitted: 5th September 2017; accepted: 30th August 2017

\begin{abstract}
This work proposes a software environment implementing a methodology for acquiring and exploiting the collective perception (CP) of Points of Interests (POIs) in a Smart City, which is meant to support decision makers in urban planning and management. This environment relies upon semantic knowledge discovery techniques and fuzzy computational approaches, including natural language processing, sentiment analysis, POI signatures and Fuzzy Cognitive Maps, turning them into a cohesive architectural blend in order to effectively gather the realistic perception of a user community towards given areas and attractions of a Smart City. The environment has been put to the test via a thorough experimentation against a massive user base of an online community with respect to a large metropolitan city (the City of Naples). Such an experimentation yielded consistent results, useful for providing decision makers with a clear awareness of the positive as well as critical aspects of urban areas, and thus helping them shape the measures to be taken for an improved city management and development.
\end{abstract}

Keywords: smart cities, fuzzy logic, text mining, sentiment analysis

\section{Introduction and Motivation}

\subsection{Context}

Data and traces that people leave on the Social Web every day can be exploited to support a plethora of different applications in a variety of domains, including security, marketing, education, and government. Specifically, in the context of
Smart Cities, being able of analyze messages, posts, tweets and tags that users share and send on the network makes it possible to derive powerful knowledge in order to understand how the citizens live in their city, how they use public spaces and facilities, how they spend their free time: that is, how they behave as citizens of a Smart City as a whole. Clearly, such information can be tremendously useful for the governance and the urban planning of

*To whom correspondence should be addressed 
the city. This is demonstrated by the huge number of research articles as well as research projects in this field. As an example, the European Unionfunded project "Urban Sensing" "has the objective of analyzing user-generated contents to understand both how cities currently operate, and how they can change in the future to better satisfy citizens' needs. To fulfill this purpose, the traditional information sources (e.g., traffic information, demographic information, interviews of citizens, etc.) are no longer sufficient on their own. Currently, it is useful, and sometimes essential, to be able to gather the opinions, interests, perceptions, complaints and habits of the citizens, and it is needed to do so in a nonintrusive way, in order to obtain information that is as truthful and accurate as possible. Indeed, such information, although difficult to acquire, allows people to understand the perception of the citizens with respect to their quality of life, as well as to identify potential hidden issues that may not be easily visible to the governors and the urban planners of the city. This means that, although it might be relatively simple for a mayor to know that a road is full of holes, it could be much more difficult for her to be aware that a newly renovated square is perceived as uncomfortable by tourists because of the presence of dirt in the streets nearby. Such kinds of perception are indeed crucial to increase the quality of life in a city, and are even more important for smart tourist destinations in order for them to attract a large number of tourists.

What clearly emerges is that gathering and interpreting the perception of citizens and tourists, by analyzing their activities related to the city on the social media, is a powerful and useful way to improve the urban ecosystem, since it may uncover hidden phenomena that might otherwise be difficult to identify; these phenomena can then represent the starting point for the planning and implementation of strategies to bring about even smarter cities. All of this information needs of course to be gathered, processed, integrated and turned into qualitative and quantitative indicators, so that it may effectively support the decision making of the government bodies of the city. Thus, this information should be integrated within the context of Decision Support System (DSS) in order to complement the decision makers' own insight, knowledge and intuitions with structured, rational models and approaches, with the ultimate purpose of improving the whole decision-making process.

With the advent of the Semantic Web and the explosion of social networks, a deluge of information has flooded the Web and can now be exploited by DSS as well for a variety of purposes and applications, thus potentially strengthening their success and pervasiveness [1]. In the context of a Smart City, it is no wonder, then, that decision support systems are becoming increasingly pivotal, as defined by IBM [2]. Unfortunately, those DSS used within such a context typically tend to rely on the data derived from the range of sensors and logs that capture the "state" of a Smart City from a quantitative perspective. However, as stated earlier, nowadays it is crucial to be able to capitalize the whole amount of subjective, qualitative but nonetheless useful information that can be found scattered across social interactions among people on the web and similar media.

The idea that this work wants to stress out is the fact that, by gathering and taking advantage of social data from people and citizens, the resulting discoveries could prove extremely useful for decision makers to enact policies, implement measures and carry out actions upon an urban area.

\subsection{Motivation}

A Smart City is a city striving to operate in a sustainable and intelligent way, via the integration of all its infrastructures, services and devices in a single technological platform based on ICT technologies, thus ensuring its economic and political efficiency, and enabling and supporting its human, social and cultural development $[3,4]$.

The government of a city have to understand the needs and the issues that the citizens are facing; otherwise, it may not be able to define the best strategies to improve the infrastructures and the services of the city itself. This is due to the fact that the most valuable resources of the city are the citizens themselves [5]. To start a transition leading towards a Smart City, a city needs to adopt proper metrics in order to set realistic goals meant to improve its citizens' quality of life. Such metrics should definitely take into account the point of view of the citizens.

\footnotetext{
${ }^{1}$ http://urban-sensing.eu/
} 
In this regard, the urban planning, along with the governance of the city, should consider not only the technical and economic aspects, but also - and most of all - the social structures of the city. A good planning process should consider all the public and private interests and issues in order to try and minimize conflicts and produce a good and sustainable planning result. According to the authors of [6], the main problem is actually to integrate all of the aforementioned issues and all of the different interests of the citizens into the planning and control processes of the city itself.

As a consequence, the main research objective of this work is to find a way to measure the perception that citizens have about their urban spaces and their different facets (quality of life, safety, environment, etc.). While pursuing this objective, one must consider that the points of view of governors and citizens are usually significantly different, and that for the former being able to capture and understand all the difficulties and daily issues of the latter can be quite complex, especially in large cities. Nonetheless, the adoption of traditional investigation tools, like interviews, surveys, and reports, is not always enough to provide truthful and accurate information. Furthermore, such tools are often expensive and time consuming, and thus they usually cannot provide results in real time, or at least in the short term. Other, more recent, approaches, like the one in [7], propose the use of Sentiment Analysis techniques, but most of the time they do not provide a quantitative measure that can help decision makers evaluate the differences in the perception and opinion of the community over time.

As stated in the previous subsection, the social web represents a valuable source of information for understanding the emotion and the perception of the citizens with respect to the quality of their urban life in the city. The main challenge this work wants to address is the one related to the extraction of knowledge from these data and to the quantification of the collective perception. The collective perception (CP) is defined as the perception that a community of users has with respect to an asset of the city (e.g., POIs, utilities, urban spaces, infrastructures).

\subsection{Proposed Solution}

This work proposes a software environment meant to acquire and exploit the collective percep- tion of people and citizens, as coming from social media, with respect to Points of Interest (POIs) of a Smart City, relying upon an innovative combination of techniques from different research areas, including semantic knowledge discovery, natural language processing, sentiment analysis, as well as fuzzy computational approaches and the concept of POI and Area signatures. This environment aims at providing decision makers with an advanced system that might be able to improve their decision processes and help them shape the present and future of a Smart City.

This approach proposed is complementary to other traditional metrics and KPIs of Smart Cities. Since a Smart City must be centered around citizens' needs, this work proposes a software environment meant to obtain their perception about the different Points of Interest of the city. By proposing a quantitative way to measure the collective perception, such information may also be used as an index to understand how the perception of the citizens varies over time, (for instance, after a new infrastructure is built), and therefore how such interventions on the city are perceived by the citizens. The environment has thus the purpose to analyze people's perceptions related to specific geographic areas, and understand how the population reacts to new urban policies.

The proposed software environment consists of:

- An approach to conceptualize the elements that characterize a Point of Interest in the city, which is preliminary (and a prerequisite) to the analysis of the messages and comments that the users of a considered community leave on the web.

- An approach, based on text mining and sentiment analysis techniques, to analyze the comments and the messages of the users of the community in order to identify the observations that such users have expressed regarding the POI and to quantify the sentiment values associated with them.

- An approach, based on Fuzzy logic, to quantify the collective perception of the community regarding a specific POI or a whole urban area.

- An application, based on Fuzzy Cognitive Map, which is able to exploit the computed value of 
collective perception in order to assess the impact of the perception of citizens about the quality of the urban area with respect to the other assets of the city.

Such an approach has been implemented in a Service-Oriented Architecture, described in Section 3, which can be used for the design and the implementation of different tools and applications for supporting decision making and urban planning of a Smart City. As a proof of concept, the whole architecture has been experimented in a real case study set in the city of Naples.

\subsection{Outline}

This paper is structured as follows. In Section 2, the methodological background of the proposed environment is reported. Section 3 describes the architecture of the environment along with its enabling technologies. In Section 4, an extensive experimentation on a large metropolitan city is reported. Section 5 provides some considerations about the experimentation results, underlying a number of theoretical and managerial implications of the proposed environment. Finally, in Section 6 conclusions are drawn.

\section{Background}

This section describes the methodological substrate underlying the proposed environment, which includes the concepts of semantics-based knowledge discovery, POI signatures and Fuzzy Cognitive Maps for Smart Cities, as detailed respectively in the following subsections.

\subsection{Semantic Knowledge Discovery}

Knowledge discovery based on semantic techniques has been progressively acquiring prominence within the context of intelligent systems as a method to extract, as automatically as possible, meaningful information from unstructured or semistructured textual data sources and turn it into a cohesive representation. In this regard, a number of methodologies and tools, either freely-accessible or covered by commercial licenses, are nowadays available for performing a variety of knowledge discovery tasks from textual sources. In this work, CONCEPTUM [8] and a custom-made Sentiment
Analysis tool based on SentiWordNet [9] have been used for carrying out the tasks related to the extraction and building of the POI knowledge base and to the evaluation of the sentiment (expressed in terms of positivity/objectivity/negativity) behind the words and expressions used to talk about a POI by the users of a community. Further details on how such activities are performed can be found in Section 3.

\subsection{POI Signatures}

As mentioned in [10], POI signatures are defined as follows. Given a web community of users who post comments and reviews about some Points of Interest (POIs) of a city (e.g., TripAdvisor), it is possible to describe their activities via a matrix $\langle U, P, O\rangle$ containing the set $U$ of users, the set $P$ of POIs and the set $O$ of observations. If a user $u_{r}$ used an observation $o_{t}$ for describing the POI $p_{s}$, the point in the matrix with coordinates $\langle r, s, t\rangle$ is marked [11]. This mechanism can thus be used to describe the activities of a single user, or the activities regarding a given POI, and so on. Specifically, it is possible to define the fuzzy set UserActivity which represents how much a given user is active in the community in the following way

$$
\text { UserActivity }_{p_{t}}(u)=\left\{\frac{b_{i}}{u_{i}}\right\}
$$

where

$$
b_{i}=\frac{\# \text { observations by user } u_{i} \text { for POI } p_{t}}{\text { max \# different observations by a user }}
$$

with $i=1, . ., n$ where $n$ is the number of users.

Similarly, it is possible to define another fuzzy set, ObsPop, which represents how much a given observation/tag is popular in the community

$$
\text { ObsPop }_{p_{t}}(o)=\left\{\frac{a_{j}}{o_{j}}\right\}
$$

where

$$
a_{j}=\frac{\# \text { times } o_{j} \text { is used forPOI } p_{t}}{\text { max\# users making a single observation for } p_{t}}
$$

with $j=1, \ldots m$ where $m$ is the number of observations.

These two fuzzy sets by themselves are enough to provide a characterization of the community in terms of active users and popularity of some observations. More interesting is a relationship that, given a specific POI, allows one to understand how 
such a POI is perceived by the users by analyzing the observations they used to describe it and how many users are interested in it. Accordingly, a fuzzy relationship is defined between the two fuzzy sets, called POI Signature, which is a fuzzy representation of the POI according to the community

$$
\begin{array}{r}
\text { POISignature }_{p_{t}}(u, o)= \\
=\text { UserActivity }(u) \times \operatorname{ObsPop}(o)
\end{array}
$$

For a single user $u_{i}$ and observation $o_{j}$, the value of the relationship is

$$
\begin{array}{r}
\text { POISignature }_{p_{t}}\left(u_{i}, o_{j}\right)= \\
=\min \left\{\text { UserActivity }_{p_{t}}\left(u_{i}\right), \text { ObsPop }_{p_{t}}\left(o_{j}\right)\right\}
\end{array}
$$

As such, the concept of POI signatures allows one to characterize a given POI in terms of the observations made by users with respect to it. These observations, for the purposes of this work, are adjectives or expressions used or mentioned by users within the context of their POI-related comments posted on online discussion boards, forums or social networks.

\subsection{Fuzzy Cognitive Maps for Smart Cities}

Fuzzy Cognitive Maps (FCMs) [12] are graphs meant to represent a variety of relationships among concepts like events, processes or states FCMs allow qualitative reasoning on the states of complex systems [13]. In a FCM, a node of the graph represents a concept $C_{i}$, connected via cause/effect relationships to other concepts, and making up a key factor of the modeled system. The strength of the relationship between concepts $C_{i}$ and $C_{j}$ is represented by a weight $w_{i j}$ : negative weights represent inverse causality, while positive ones mean direct causality. The activation value $A_{i}$ of concept $C_{i}$ is given by

$$
A_{i}^{k+1}=f\left(A_{i}^{k}+\sum_{j=1, j \neq i}^{n} A_{j}^{k} w_{j i}\right)
$$

where $A_{i}^{k+1}$ is the activation level of the concept $C_{i}$ at the $k+1$ iteration, $A_{j}^{k}$ is the activation level of the concept $C_{j}$ at the $k$ iteration, $w_{j i}$ is the weight between concepts $C_{j}$ and $C_{i}$, and $f$ is a threshold function. Considering that a FCM represents causeeffect relationships among different concepts, it has been widely employed for supporting what-if analysis. Indeed, it is possible to consider an initial scenario of simulation given by a activation vector $S^{0}=\left(s_{1}, \ldots, s_{n}\right)$ where $s_{i} \in[0,1]$ is the activation level of concept $C_{i}$. Starting from the activation vector $S^{0}$ of the initial scenario, it is possible to compute the activation values of the concepts in the following iteration of the map, resulting in a set of transitions $A^{0} \rightarrow A^{1} \rightarrow \ldots$. When a limit cycle is found or a fixed state is found, it is possible to know which is the new state of the map or of specific concepts of interest. In such a way, it is clear that, starting from a baseline scenario, it is possible to simulate what will happen when the state of a specific concept changes, thus performing what-if analysis.

In the context of Smart Cities, many papers explored the use of FCMs as an analytical and decision-support tool in different contexts like, for instance, to support urban resilience analysis [14], green issues [15], urban planning [16]. The authors in [10] proposed the use of FCMs as means to model the mental representations that communities of citizens or experts have shaped with respect to urban issues. In such a case, the urban planners and the decision makers have a powerful tool to analyze the impact of the collective perception that the citizens possess about a specific city asset (e.g. quality of transportation, level of safety, etc.) and to understand how such a perception may influence the other assets of the city. In order to be able to activate the FCM with the collective perception of the citizens, so as to perform scenario analysis, it is firstly needed to identify high level objectives for the Smart City (i.e. why are we performing such scenario analysis?). Starting from such objectives, it is possible to define a set of qualitative indicators related to the different city assets (e.g. the level of safety as perceived by the community, the quality of the urban area, etc.). Such indicators, together with the above mentioned objectives allow us to define a Fuzzy Cognitive Map supporting the reasoning on different perspectives that the stakeholders of the city have with regards to the high-level objectives such as "improving quality of life", "improving safety", "reducing pollution" and so on. Further details on the definition and use of Fuzzy Cognitive Map activated by the collective perception can be found in [10]. In the evaluation section (Section 4) a complete example of the use of an FCM 
for performing what-if analysis in a real case will be provided.

\section{An Environment for Extracting and Evaluating the Users' Per- ception of POIs}

The environment proposed in this work is a software architecture made up of a number of different components, whose fundamental purpose is to find information related to POIs among online sources and understand how such POIs are perceived by users. Specifically, the proposed architecture integrates a number of different approaches and techniques. Some of them, like those responsible for the analysis and conceptualization of texts, are based on advanced knowledge discovery methods and tools, which have been described by the authors in previous works ([8], for example) and have been customized for the specific problem accordingly. Others, on the other hand, are novel altogether, including the approach for the identification and measurement of the value of collective perception, based on Fuzzy Logic and on the concept of User Signature [11], which has been reformulated by the authors in order to apply it to the context of users' opinions about specific resources.

As such, the environment includes the following components:

1. a Knowledge Extractor and Builder module (KEB), which encapsulates software components for crawling texts from online sources and processing them via lexical analysis, NLP and wikification techniques, as well as for building taxonomies from the texts themselves;

2. a Sentiment Detector and Analyzer module (SDA), whose purpose is to find textual references to POIs from online messages and evaluate their sentiment values in terms of the positivity, negativity or neutrality of the opinions expressed by online users;

3. a Collective Perception Identifier module (CPI), meant to produce the POI signatures for each POI, or the Area signature for an entire area containing more than one POI, thus evaluating the collective perception of the community with respect to the POIs or the Area. The CP is then used in order to perform scenario analysis by using Fuzzy Cognitive Maps.

The conceptual architecture of the proposed environment is depicted in Figure 1.

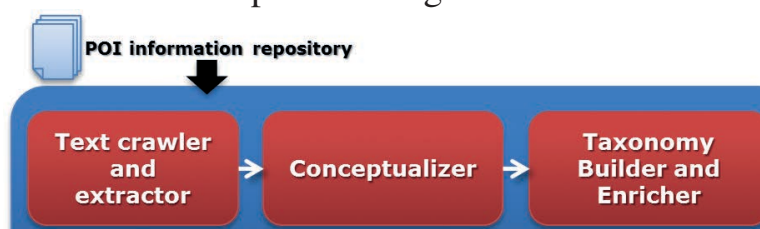

Knowledge Extractor and Builder (KEB)

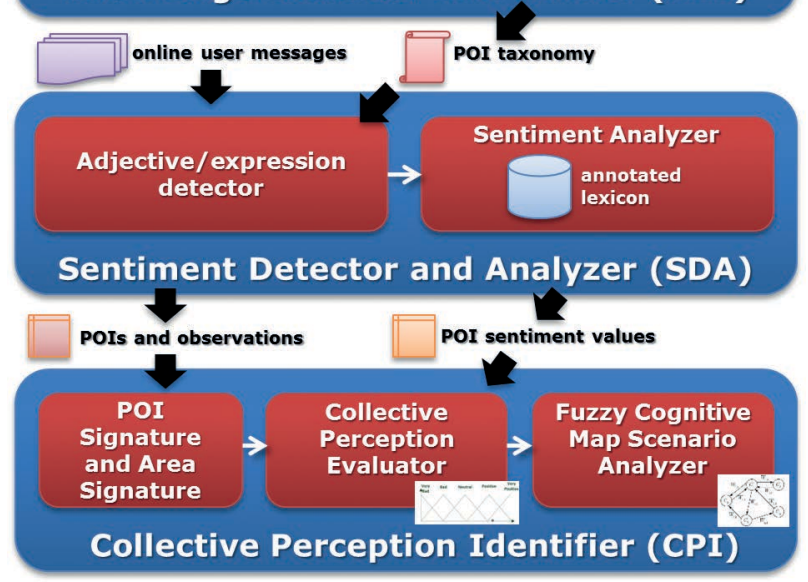

Figure 1. Conceptual architecture of the environment.

\subsection{Extraction and Building of the POI Knowledge Base}

The Knowledge Extractor and Builder module (KEB) is responsible of acquiring information about the POIs to be considered and turning it into a structured taxonomy of relevant concepts. Given a POI, such a module implements the procedure made up of the following steps.

\subsubsection{Text Crawling and Extraction}

Textual repositories containing relevant information about the POI are crawled (step 1.1 from Table 1). Specifically, at this stage of the work the Wikipedia page (article) describing the POI is the one considered. This choice was made to provide the system with an information summary for the selected POI, given the general availability of Wikipedia articles and the user-driven knowledge usually contained within them. Thus, the automatic crawling of this information overcomes the need to manually identify relevant tags for the specific POI and painstakingly annotate it accordingly. Besides, the user-driven nature of such information makes 
the subsequent phases of the whole process easier, especially concerning the gathering of users' observations (as described later in Section 3.2) and specifically the detection of POI references from the user community (Section 3.2.1), since users may be in principle more inclined to use similar terms or expressions as those found within the corresponding Wikipedia article.

Since the length of an article may vary and a deluge of potentially irrelevant information may flood the system, in order to minimize the possibility of ending up with an excessive number of irrelevant terms, only the introduction paragraph of the page is currently taken into account. In the event that an introduction paragraph is not present, the first section (with the exception of the "History" section) is considered; it might be also worth mentioning that, when considering a sufficiently small number of POIs, a supervision of this mechanism may be employed so that only the most relevant blocks of text are actually used and passed to the system.

Further developments of this work may come to include specific information pages from additional official and informal sources, including the tourism websites of the city, province or region where the considered POI is located.

\subsubsection{Conceptualization}

A conceptualization phase is carried out upon the retrieved text, by using the corresponding service provided by the CONCEPTUM system [8]. This phase (corresponding to step 1.2 from Table 1) performs natural language processing upon the given text and returns the semantically most relevant concepts from the text by cross-referencing a common-sense knowledge base (Wikipedia). As such, the identified concepts are not necessarily those with the highest number of occurrences within the text: the number of their occurrences is weighted against their relevance score according to their respective presence and affinity in documents (articles) of the common-sense knowledge base.

Specifically, this conceptualization phase processes the retrieved text as follows:

- the text is preliminarily cleaned by removing punctuation, stop-words etc.;
- the cleaned text is tagged with Part-Of-Speech (POS) tags and lemmatized accordingly;

- a shallow syntax parsing is performed upon the text;

- the information from POS tagging and syntax parsing, along with some language-dependent proximity rules, is used to compose terms (e.g. adjective + noun, contiguous upper-case nouns etc.), according to the process described in [17];

- while the above mentioned language processing is performed, a Wikification process of the original text, based on Wikipedia Miner [18] and originally applied in $[19,20]$ is carried out in order to produce a number of topics from the Wikipedia common-sense knowledge base that are semantically relevant to the given text;

- a matching is performed between the composed terms from the language processing step and the common-sense topics from the wikification step, by using syntactical distances (e.g. Levenshtein, Jaccard) and synonym expansion. Each match is thus assigned a matching score: those matches scoring higher than a given percentage threshold (currently 70\%) are deemed good;

- the resulting good matches (composed termtopic pairs) correspond to the most relevant semantic concepts from the input text; specifically, the topic element from the pair is selected as the concept to be returned for each match.

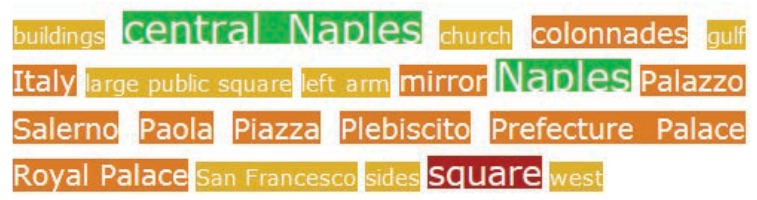

Figure 2. Terms returned from a text describing the POI of Piazza Plebiscito, Naples, organized in a tag cloud according to their semantic relevance.

A sample output of the terms returned from a text describing a POI (Piazza Plebiscito, Naples), organized in a tag cloud according to their respective relevance score, is shown in Figure 2, before matching them with topics from the Wikification process. Figure 3, instead, shows the term-topic pairs eventually derived from the conceptualization phase, ordered from left to right by decreasing relevance score. 
Table 1. Summary of the process implemented by the proposed architecture, underlying the input, output and purpose/motivation for each of its steps.

\begin{tabular}{|c|c|c|c|c|}
\hline Step \# & Step name & Input & Output & Purpose/motivation \\
\hline 1.1 & $\begin{array}{l}\text { Text crawling and } \\
\text { extraction }\end{array}$ & $\begin{array}{l}\text { Name of the POI, Wikipedia } \\
\text { page about the POI }\end{array}$ & $\begin{array}{l}\text { Paragraph of text describing } \\
\text { the POIs, as extracted from } \\
\text { the "Introduction" section of a } \\
\text { Wikipedia article or from the } \\
\text { latter's first paragraph ("His- } \\
\text { tory" excluded) }\end{array}$ & $\begin{array}{l}\text { Automatic retrieval of textual informa- } \\
\text { tion about a given POI. The alterna- } \\
\text { tive would have been a manual input of } \\
\text { knowledge about the POI itself. }\end{array}$ \\
\hline 1.2 & Conceptualization & $\begin{array}{l}\text { Textual paragraph describing } \\
\text { the given POI from } 1.1\end{array}$ & $\begin{array}{l}\text { Pairs of term-topic, where term } \\
\text { is a relevant term identified } \\
\text { within the text, and topic is a } \\
\text { semantically-relevant topic for } \\
\text { the identified term as found } \\
\text { in the Wikipedia commonsense } \\
\text { knowledge base; for each pair, } \\
\text { the topic is selected as the rele- } \\
\text { vant "concept" to be associated } \\
\text { with the POI }\end{array}$ & $\begin{array}{l}\text { Automatic extraction of relevant con- } \\
\text { cepts that describe a POI. This replaces } \\
\text { the error-prone and time-consuming } \\
\text { process of manually extracting relevant } \\
\text { terms from a given text. }\end{array}$ \\
\hline 1.3 & $\begin{array}{l}\text { Taxonomy Build- } \\
\text { ing and Enrich- } \\
\text { ment }\end{array}$ & $\begin{array}{l}\text { Relevant concepts for a POI } \\
\text { from } 1.2\end{array}$ & $\begin{array}{l}\text { A taxonomy describing the } \\
\text { POI, made up of the input } \\
\text { concepts each enriched with } \\
\text { a number of potential syn- } \\
\text { onyms, as derived from the } \\
\text { alternative "senses" found in } \\
\text { the Wikipedia commonsense } \\
\text { knowledge base }\end{array}$ & $\begin{array}{l}\text { Creation of a small knowledge base for } \\
\text { the given POI, in a fully-automated way. } \\
\text { The alternative was a manual process. }\end{array}$ \\
\hline 2.1 & $\begin{array}{l}\text { Detection of ad- } \\
\text { jectives and ex- } \\
\text { pressions }\end{array}$ & $\begin{array}{l}\text { Taxonomy for a given POI } \\
\text { from 1.3, social network } \\
\text { messages (from an Instagram } \\
\text { group for the purposes of the } \\
\text { experimentation described in } \\
\text { this paper) }\end{array}$ & $\begin{array}{l}\text { List of observations, i.e. adjec- } \\
\text { tives and expressions, found in } \\
\text { the social messages referring to } \\
\text { the given POI }\end{array}$ & $\begin{array}{l}\text { Automatic identification of "qualifiers" } \\
\text { for a given POI as employed by people } \\
\text { discussing it on social networks. The al- } \\
\text { ternative was a manual process. }\end{array}$ \\
\hline 2.2 & $\begin{array}{l}\text { Sentiment analy- } \\
\text { sis }\end{array}$ & $\begin{array}{l}\text { List of observations for the } \\
\text { given POI from } 2.1\end{array}$ & $\begin{array}{l}\text { List of observations for the } \\
\text { given POI, each with its cor- } \\
\text { responding sentiment value, } \\
\text { as checked against sentiment- } \\
\text { annotated lexicons }\end{array}$ & $\begin{array}{l}\text { Understanding the sentiment behind the } \\
\text { observations made by people when dis- } \\
\text { cussing a given POI. The alternative was } \\
\text { a manual process. }\end{array}$ \\
\hline 3.1 & $\begin{array}{l}\text { Production of } \\
\text { POI and Area } \\
\text { Signatures }\end{array}$ & $\begin{array}{l}\text { List of observations for a POI } \\
\text { from } 2.1\end{array}$ & $\begin{array}{l}\text { POI and Area Signatures, } \\
\text { which are matrices containing } \\
\text { the observations provided by } \\
\text { all the users }\end{array}$ & $\begin{array}{l}\text { Production of the POI and Area signa- } \\
\text { tures, which are pivotal in the compu- } \\
\text { tation of the collective perception in the } \\
\text { subsequent and final step of the process; } \\
\text { these elements play a fundamental role } \\
\text { in the novel approach proposed for com- } \\
\text { puting the CP itself. }\end{array}$ \\
\hline 3.2 & $\begin{array}{l}\text { Computation of } \\
\text { the collective } \\
\text { perception }\end{array}$ & $\begin{array}{l}\text { POI and Area Signatures from } \\
3.1 \text {, sentiment-annotated ob- } \\
\text { servations from } 2.2 \text { and } \alpha-\text { cut } \\
\text { parameter }\end{array}$ & $\begin{array}{l}\text { Collective perception of POI or } \\
\text { Area, which is the ultimate out- } \\
\text { put of the whole process }\end{array}$ & $\begin{array}{l}\text { Production of a quantitative value meant } \\
\text { to describe how a POI and/or an area are } \\
\text { actually perceived by the users, by com- } \\
\text { puting the value of collective perception } \\
\text { for the POI or the Area, resorting to a } \\
\text { Fuzzy Inference System processing the } \\
\text { sentiment scores of the observations ex- } \\
\text { tracted from the POI (or Area) Signa- } \\
\text { tures via the } \alpha-\text { cut operator. }\end{array}$ \\
\hline
\end{tabular}




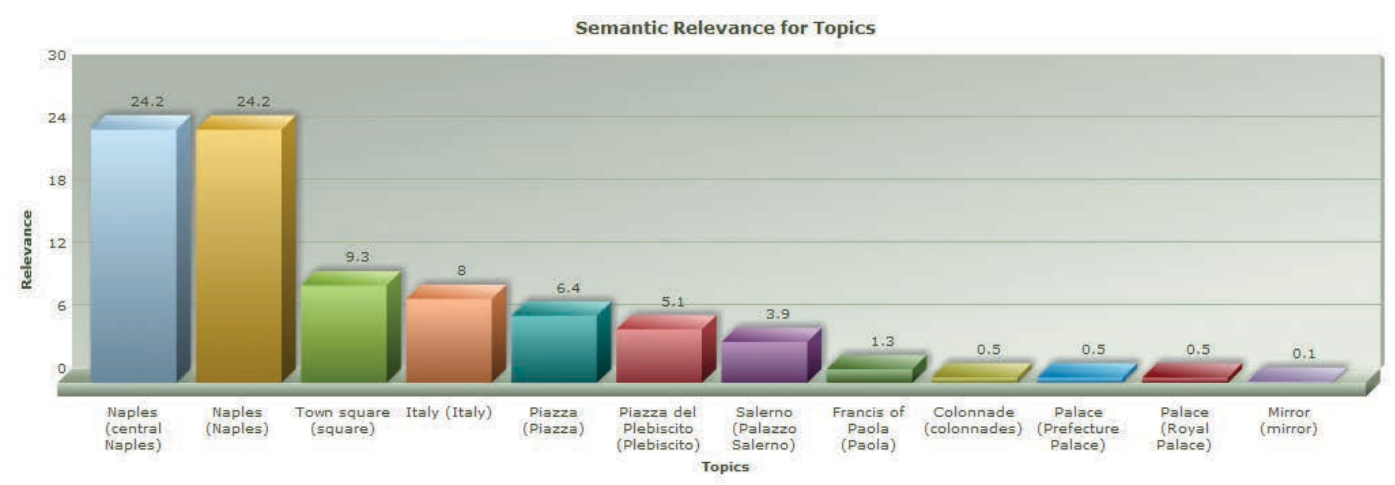

Figure 3. Term-topics pairs (with terms enclosed within brackets) derived from the conceptualization process, ordered from left to right by decreasing semantic relevance.

\subsubsection{Taxonomy Building and Enrichment}

A knowledge base is created from the returned concepts (step 1.3 from Table 1). Currently, the generated knowledge base for each POI is a onelevel taxonomy including among its terms the concepts obtained from the previous step. Furthermore, a subsequent enrichment step is performed in order to associate with the POI's name a list of potential synonyms or corresponding alternate spellings: this is done via another Wikification-based process provided by CONCEPTUM, which returns a number of "alternate" senses for the POI's name, as featured in the Wikipedia knowledge base. For instance, for the "Subterranean Naples" POI, synonyms and additional terms returned include "Subterranean Caves", "Underground Naples", "Naples City Caves", etc. A refinement that is under research in this regard is related to the creation of a multi-level taxonomy or a full-fledged ontology, by taking advantage of another service provided as a beta version by CONCEPTUM, which detects a subset of relationships (namely hypernymy, relatedness and hierarchy) for the identified concepts of each POI, in order to generate a small semantic graph containing them.

\subsection{Gathering and Analysis of Users' Ob- servations from Online Sources}

Once the knowledge bases for the considered POIs are created, the Sentiment Detector and Analyzer module (SDA) takes care of scanning users' comments from online forums, message boards or social networks, in order to (i) find adjectives and expressions related to the considered POIs and (ii) understand and quantify their positivity/negativity values. These two activities are detailed below.

\subsubsection{Detection of Adjectives and Expressions Related to POIs}

The first activity revolves around the identification of comments, posts and texts uploaded by users where the considered POIs are mentioned, either explicitly or implicitly (step 2.1 from Table 1 ). The bulk of such texts is therefore crawled and scanned in order to detect the presence of a POI "reference", i.e. either a POI's explicit name along with its synonyms/alternate spellings, or some of the concepts associated with it via the generated taxonomy. For each sentence containing a POI reference, adjectives directly linked to the reference, as well as expressions as predicative nominals linked by copulas to the reference, are detected and retrieved via syntax parsing. The result of this activity produces a map structure whose keys are the POIs referenced within the scanned texts and whose values are the corresponding adjectives and expressions referring to them.

\subsubsection{Analysis of the Sentiment Associated with the Detected Adjectives and Expressions}

The map produced by the previous activity is then passed to the submodule responsible for the sentiment check (see step 2.2 in Table 1). Specifically, for each POI, the adjectives and expressions related to it are checked against a lexicon annotated with sentiment values in order to establish their potential positive, negative or objective value. The lexicons currently used by the system are SentiWordNet [9] for the English language, and the one used in [21] as a byproduct of three lexicons (SentiWordNet, MultiWordNet and WordNet itself) for the Italian language. The submodule returns, for each adjective/expression, values in the $[0,1]$ range that represent the adjective/expression's positivity, 
negativity, or neutrality, whose sum total is 1 . As such, for the $i$-eth POI, its corresponding positivity $\left(S p_{i}\right)$, negativity $\left(S n_{i}\right)$ or neutrality $\left(S u_{i}\right)$ values are computed as follows

$$
\begin{aligned}
& S p_{i}=\frac{\sum_{k=1}^{K} p_{k}}{K} \\
& S n_{i}=\frac{\sum_{k=1}^{K} n_{k}}{K} \\
& S u_{i}=\frac{\sum_{k=1}^{K} u_{k}}{K}
\end{aligned}
$$

where $K$ is the total number of adjectives/expressions found and evaluated, and $p_{k}$, $n_{k}$ and $u_{k}$ are the $k$-th positivity, negativity and neutrality value, respectively, for the $k$-th adjective/expression.

\subsection{An Environment for Extracting and Evaluating the Users' Perception of POIs}

\subsubsection{Evaluation of the Collective Perception for POIs via POI Signatures}

The Collective Perception Identifier module (CPI) is responsible for the computation of the collective perception starting from the observations and the sentiment identified by the SDA module described in the previous section. First of all, the module produces the POI signatures for all of the selected POIs (see step 3.1 in Table 1). As an example, let us consider Table 2 which contains, within its rows, the observations extracted in step 2.1 by the SDA module and, within its columns, the users who have made such observation in their comments. For computing the POI Signature, it is necessary to evaluate the UserActivity and the ObsPop for each user and observation using equations 1 and 3 . Such values are reported on the last row and on the last column in Table 2. Subsequently, it is possible to evaluate the value of the POI Signature relation by using eq. 5 , and in particular, by using the $\min$ as a $t-$ norm. Such values are reported in Table 3 . The POI Signature can be used to evaluate the collective perception. Specifically, it is possible to use all the observations extracted by the SDA module, but in such case the observations that are very frequent and the ones that are unusual are treated in the same way. To avoid such a behavior, it is possible to consider just a subset of all the observations. Specifically, by using an alpha-cut operation on the fuzzy relation POI Signature, only the pairs $\left\langle u_{i}, o_{j}\right\rangle$ whose value of POI Signature is greater than alpha are considered. For instance, in Table 3, the values highlighted in red represent the pairs $\left\langle u_{i}, o_{j}\right\rangle$ with $\alpha$-cut $>0.5$. The observations contained in the pairs considered after the $\alpha$-cut operation represent a bag of observations that convey the collective perception of the community (specifically, for the users who are more active). Considering this bag of observations and the sentiment scores of such words as computed by the SDA module, it is possible to obtain the final value of the $\mathrm{CP}$.

Table 2. Example of observations for a POI with UserActivity and ObsPop

\begin{tabular}{c|cccc|c} 
Observation & $u_{1}$ & $u_{2}$ & $u_{3}$ & $u_{4}$ & ObsPop \\
\hline amazing & $\mathrm{X}$ & & & & 0.33 \\
serene & $\mathrm{X}$ & $\mathrm{X}$ & & & 0.66 \\
beautiful & $\mathrm{X}$ & & $\mathrm{X}$ & $\mathrm{X}$ & 1 \\
disgusting & & $\mathrm{X}$ & & $\mathrm{X}$ & 0.66 \\
\hline UserActivity & 1.00 & 0.66 & 0.33 & 0.33 &
\end{tabular}

Table 3. Example of POI Signature

\begin{tabular}{c|cccc|c} 
Observation & $u_{1}$ & $u_{2}$ & $u_{3}$ & $u_{4}$ & ObsPop \\
\hline amazing & 0.33 & & & & 0.33 \\
serene & 0.66 & 0.66 & & & 0.66 \\
beautiful & 1 & & 0.33 & 0.33 & 1 \\
disgusting & & 0.66 & & 0.33 & 0.66 \\
\hline UserActivity & 1.00 & 0.66 & 0.33 & 0.33 &
\end{tabular}

Table 4. If-Then rules to achieve CP (in case of $\mathrm{O}=$ Low)

\begin{tabular}{c|ccc|c} 
& $\mathbf{P}$ & O & N & CP \\
\hline R1 & H & L & L & VP \\
R2 & H & L & M & P \\
R3 & H & L & H & N \\
R4 & M & L & L & P \\
R5 & M & L & M & N \\
R6 & M & L & H & B \\
R7 & L & L & L & N \\
R8 & L & L & M & B \\
R9 & L & L & H & VB
\end{tabular}

In order to evaluate the collective perception related to a single POI (see step 3.2 in Table 1), a 
Fuzzy Inference System (FIS) is used, whose rule base is reported in Table 4, so that it is possible to obtain the value of the $\mathrm{CP}$ starting from the sentiment scores $S p_{i}, S n_{i}$ and $S u_{i}$ (Eq. 8 - 10) for each observations we have selected with the $\alpha$-cut operation.

Such scores are intended as the inputs of the FIS and their membership functions are reported in Figure 4. The FIS allows us to obtain a value for the collective perception, obtained by defuzzifying the output of the FIS.

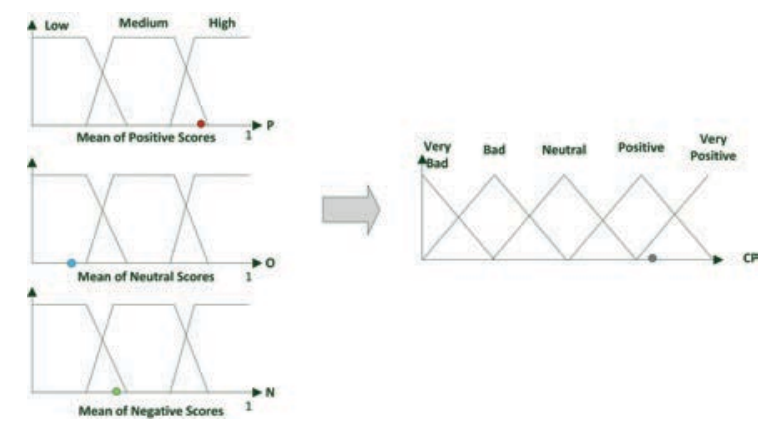

Figure 4. Fuzzy variables and membership of the FIS for computing the collective perception

The CP value helps us with the estimation of the perception that a community has with respect to the analyzed POI. Depending on the type of the selected comments as well as on the characteristics of the considered community, such $\mathrm{CP}$ can refer to different, specific assets of the city, allowing us to execute several kinds of what-if analysis as mentioned above. For instance, such collective perception may refer to wider concepts like the quality of the urban space as perceived by the community, or it can refer to more specific assets like the quality of the transportations or the perceived safety. In such cases, it is required that the comments processed by the SDA module are related only to that specific asset. By leveraging the taxonomy created by the KEB module, it is possible to select only those comments that are relevant for the kind of what-if analysis chosen and the related city assets.

\subsubsection{Area Signature}

In most cases, the evaluation of the collective perception of a whole geographical area, instead of a single POI, is of relevance (see step 3.2 in Table 1 as well). The collective perception of a whole area is computed by aggregating the POI Signatures of all the POIs that are located in that area. To group the POI Signatures the approach proposed in [11], based on the Ordered Weighted Average (OWA) operator [22], is used

$$
\begin{array}{r}
\text { Area }_{\text {Signature }}\left(u_{i}, o_{j}\right)= \\
=O W A_{\text {POIm } \in \text { Area }}^{L Q}\left(\operatorname{POI}_{\text {Sig }_{\text {POIm }}}\left(u_{i}, o_{j}\right)\right)
\end{array}
$$

The attractiveness of OWA comes from its ability to combine pieces of information using linguistic quantifiers (LQ) defining both range and degree of contribution of individual pieces toward the overall value. Different linguistic quantifiers $L Q$ allows one to control the degree of exactness of the description of the group of POIs. A coarse-grained characterization will be obtained if the quantifier is $L Q=\max$, while a narrower characterization will be obtained with the quantifier $L Q=\min$ as only the most common pairs $\left(u_{i}, o_{j}\right)$ will be included in the Area Signature. Roughly speaking, the Area Signature associates a bag of observations with the area so as to reflect the perceptions and the opinions of the community on its POIs. To transform this bag of observations into the value of Collective Perception, the same approach used for a single POI is employed.

Please note that there are two degrees of freedom to modify the characterization of the area:

- by changing the linguistic quantifier LQ in Eq. 11

- by changing the $\alpha$-cut in Eq. 5. Indeed, by using a lower value of the $\alpha$-cut, the POI Signature will contain less frequent pairs $\left(u_{i}, o_{j}\right)$ as well, leading to a wider and less precise characterization of the area, but also revealing meaningful observations although not so popular. With greater values of $\alpha$-cut a dual behavior is obviously obtained.

\section{Experimentation of the System}

After a preliminary evaluation carried out earlier in order to assess the feasibility of the proposed approach (as described in [10]), a more comprehensive experimentation has been performed upon the Metropolitan City of Naples, Italy. 


\subsection{Data}

In this regard, an area of Naples, downtown, was selected, upon which decision makers may want to perform their research. The area, depicted in Figure 6, has an extension of $1.57 \mathrm{~km}^{2}$, and includes eight tourist attractions: the Royal Palace of Naples, the San Carlo Theater, Piazza Plebiscito, Castel Nuovo, The Molosiglio Gardens, Galleria Umberto I, Subterranean Naples, the Basilica of San Francesco di Paola and the Church of Santa Maria Francesca.

From these eight POIs, a representative sample of 4 points was selected:

- 2 strongly attractive POIs (according to the evaluations the POIs received on Google Maps): Subterranean Naples and Piazza Plebiscito;

- 2 weakly attractive POIs: Gardens of Molosiglio and the Church of Santa Maria Francesca.

In this scenario, the attractiveness of the POIs depends on the overall ratings of such places on Google Maps.

The position of the four POIs is depicted on the map featured in Figure 5.

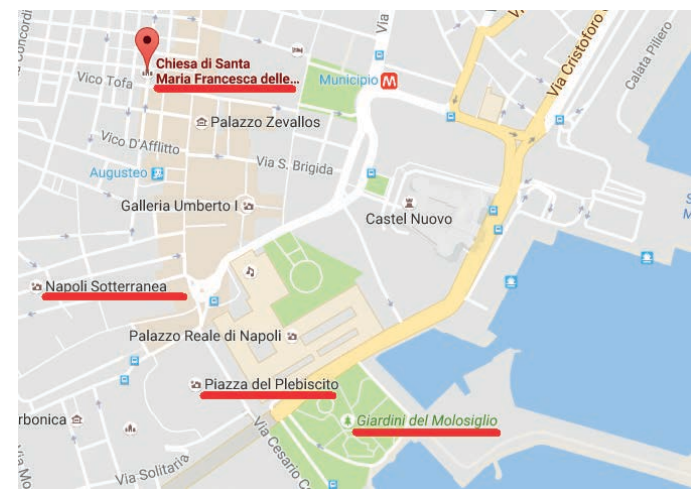

Figure 5. The POIs of the considered area chosen for the experimentation, namely Subterranean

Naples ("Napoli Sotterranea") and Piazza

Plebiscito [strongly attractive POIs], and the Gardens of Molosiglio ("Giardini di Molosiglio") and the Church of Santa Maria Francesca ("Chiesa

di Santa Maria Francesca")[weakly attractive POIs].

The user community considered was "NapoliDaVivere", an Instagram group with more than 22000 followers and 30 users (who are the administrators of the group). 30 comments for each POI were analyzed in order to construct the POI signatures and then evaluate the collective perception of the selected area.

\subsection{Method}

\subsubsection{POI Signature}

Following the approach described in Section 3, the Knowledge Extractor and Builder (KEB) module generates a taxonomy of the most relevant concepts related to the selected POIs. The Sentiment Detector and Analyzer (SDA) module scans the users' comments for the selected POIs in order to identify the most relevant observations (adjectives and expressions) which refer to important concepts related to the POI. In this process, the SDA leverages the taxonomy of concepts created by the KEB for understanding whether an adjective or an expression actually refers to the POI. The identification of all the observations for the POIs allows the system to compute the POI Signatures. Figures 7 thru 10 show the pairs of users and observations $\left(u_{i}, o_{j}\right)$ for each POI. Users are listed along the rows of the tables, while the observations along their columns. A " 1 " in the cell $\left(u_{i}, o_{j}\right)$ indicates that the user $u_{i}$ expressed the observation $o_{j}$ in his/her comment regarding that POI. In the last column, the values of the UserActivity (Eq. 1) are reported, indicating the degree of activity of the user (i.e. how many observations he/she used) with respect to all the other users. In the last row, the values of ObsPop (Eq. 3) are listed, representing the popularity of the observation among the users.

The value of the POI Signature is evaluated by using Eq. 5 for the four POIs. In this experimentation scenario, two different values of $\alpha$-cut are used: $\alpha$-cut $>0.5$ to select the most common pairs of users and observations, and $\alpha-c u t>0.3$ to select a larger number of pairs, even if they are less frequent. In this way, it is possible to show the effect of the $\alpha$-cut on the collective perception value.

The SDA module computes the sentiment scores for each observation. From these, the observations that are too objective (i.e. with a value of objectiveness $O>0.5$ ) are removed, since they do not contribute to the value of collective perception.

With an $\alpha$-cut $>0.5$, the following bags of observation for each POI are obtained: 


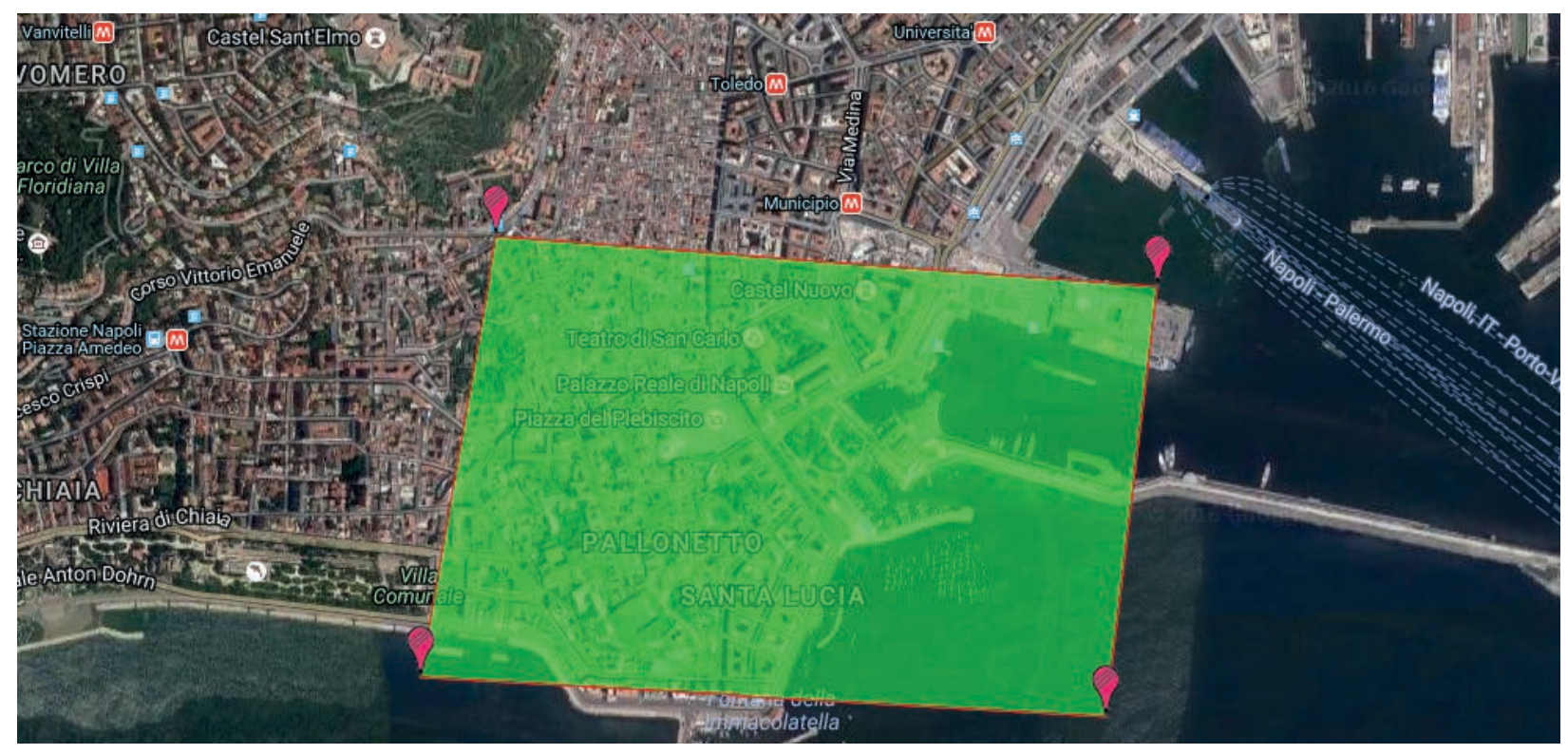

Figure 6. Area of Naples, downtown, chosen for the experimentation, with an extension of 1.57 square meters.

\begin{tabular}{|c|c|c|c|c|c|c|c|c|c|c|c|c|c|c|c|}
\hline Users & Observations & wonderful & interesting & historical & guide & peaceful & centre & uncomfortable & informative & suggestive & worthful & ancient & charming & Obsuser & UserActivity \\
\hline & U1 & 1 & & & & & & & \begin{tabular}{c|} 
\\
\end{tabular} & & & & & & 0,500 \\
\hline & $\mathrm{U} 2$ & & 1 & & & & & & & & 1 & 1 & & & 0,600 \\
\hline & $\mathrm{U} 3$ & & & & & & 1 & & & & 1 & & & & 0,400 \\
\hline & $\mathrm{U} 4$ & & & & & & & 1 & & & & & & & 0,200 \\
\hline & $\mathrm{U} 5$ & 1 & & & & 1 & & 1 & 1 & & & & & $\overline{4}$ & 0,800 \\
\hline & U6 & & & & & & & & 1 & & & & & & 0,200 \\
\hline & $\mathrm{U} 7$ & & & & & 1 & & & 1 & & 1 & & & 3 & 0,600 \\
\hline & $\mathrm{U} 8$ & 1 & & & & & 1 & & & & & & & 2 & 0,400 \\
\hline & U9 & 1 & & & 1 & & & 1 & 1 & & & & 1 & 5 & 1,000 \\
\hline & U10 & 1 & & & & & & & & & 1 & & & $\overline{2}$ & 0,400 \\
\hline & U11 & & & 1 & & & & & & & & & & & 0,200 \\
\hline & $\mathrm{U} 12$ & 1 & & & & & & 1 & & & & & & & 0,400 \\
\hline & U13 & & & & & 1 & & & & & & 1 & & & 0,400 \\
\hline & U14 & & & & & & 1 & & & & 1 & & & & 0,400 \\
\hline & U15 & 1 & & & & & & 1 & & 1 & 1 & & & & 0,800 \\
\hline & U16 & & 1 & & & & & & & & & & & 1 & 0,200 \\
\hline & U17 & & & & & & & 1 & 1 & & & & & & 0,400 \\
\hline & U18 & & & & 1 & & & & & & 1 & & & 2 & 0,400 \\
\hline & U19 & & & & & 1 & & & & & & & & & 0,200 \\
\hline & $\mathrm{U} 20$ & & & 1 & & & & 1 & & & 1 & & & & 0,600 \\
\hline & U21 & 1 & & & & & & & 1 & & & & 1 & & 0,600 \\
\hline & $\overline{\mathrm{U} 22}$ & & & & 1 & & & & 1 & & & & & & 0,400 \\
\hline & $\mathrm{U} 23$ & 1 & & & & & & & & & 1 & 1 & & & 0,600 \\
\hline & U24 & & & & & & & 1 & & & & & 1 & & 0,400 \\
\hline & $\mathrm{U} 25$ & & & 1 & & & & & 1 & & & & & & 0,400 \\
\hline & U26 & & & & & 1 & & & & & 1 & & 1 & & 0,600 \\
\hline & U27 & 1 & & & & & & 1 & & & & & & & 0,400 \\
\hline & $\mathrm{U} 28$ & & & & & & & & 1 & 1 & & & & & 0,400 \\
\hline & $\mathrm{U} 29$ & & 1 & & & & & & & 1 & & & & & 0,400 \\
\hline & U30 & 1 & & & & & & & & 1 & & & 1 & & 0,600 \\
\hline & absfreq & & & & & & & & 10 & & 10 & & 5 & & \\
\hline & ObsPop & 1,000 & 0,273 & 0,273 & 0,273 & 0,455 & 0,273 & 0,818 & 0,909 & 0,364 & 0,909 & 0,273 & 0,455 & & \\
\hline
\end{tabular}

Figure 7. POI Signature for POI1 (Subterranean Naples) 


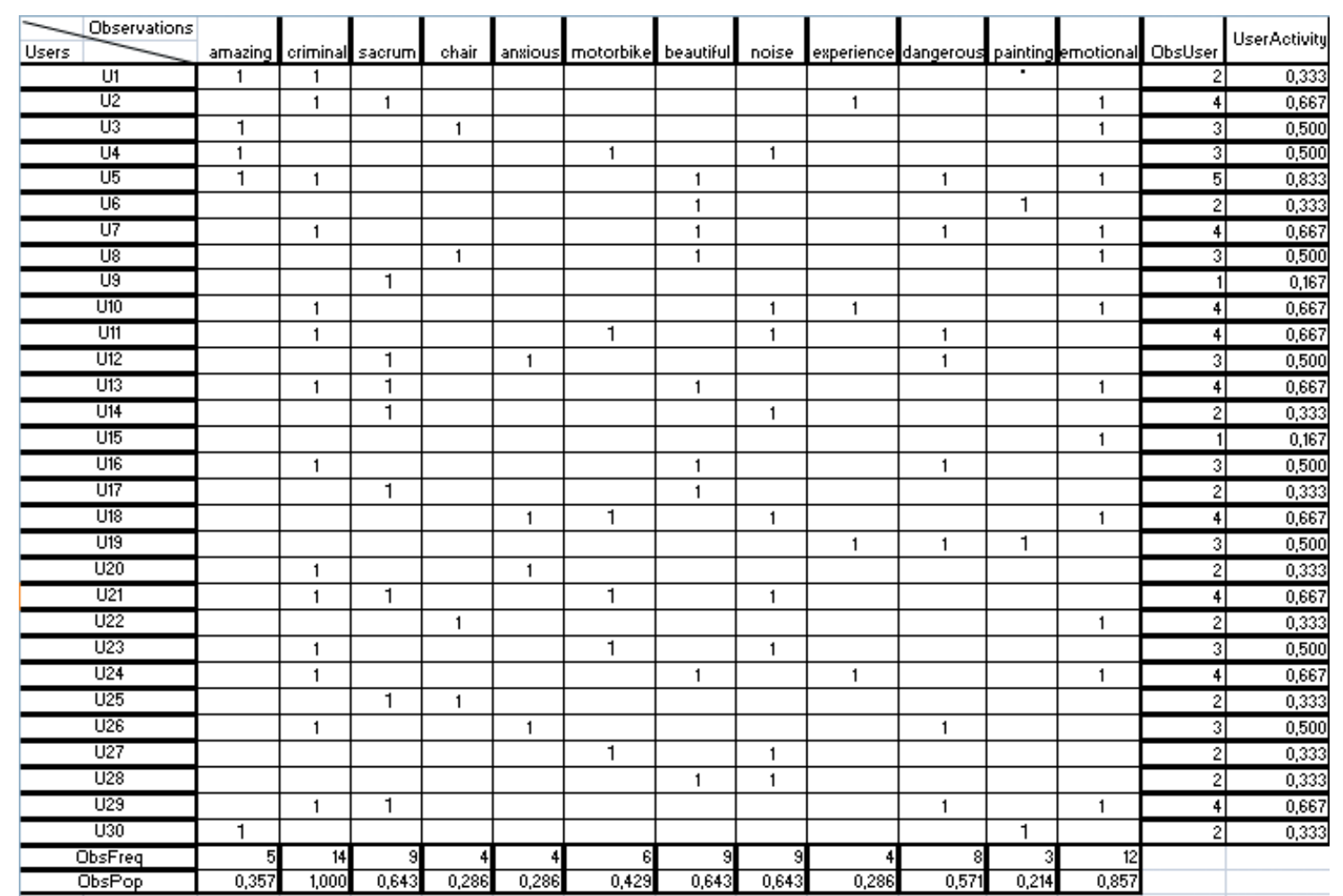

Figure 8. Signature for POI2 (Church of Santa Maria Francesca)

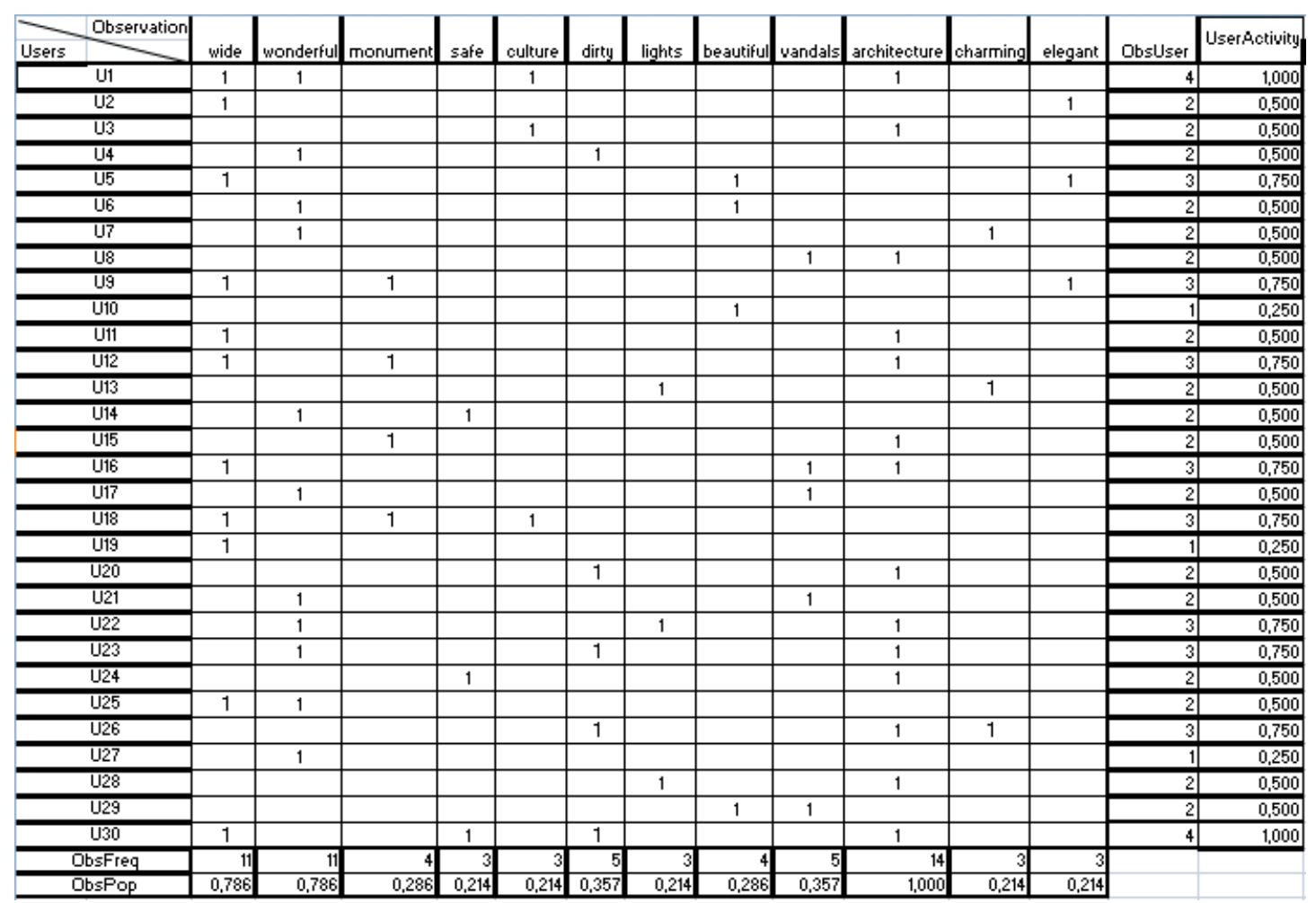

Figure 9. Signature for POI3 (Piazza Plebiscito) 


\begin{tabular}{|c|c|c|c|c|c|c|c|c|c|c|c|c|c|c|}
\hline Users & garden & wonderful & dirty & abusive & peaceful & vagabonds & monument & walking & suggestive & worthful & fountain & charming & Obsuser & UserActivity \\
\hline $\mathrm{U} 1$ & & & & & 1 & & & & 1 & & & & \begin{tabular}{r|}
2 \\
\end{tabular} & 0,400 \\
\hline$\overline{\mathrm{U} 2}$ & & & & 1 & & & & & & & 1 & & 2 & 0,400 \\
\hline $\mathrm{U} 3$ & 1 & 1 & & & & 1 & & & & 1 & & & 4 & 0,800 \\
\hline 04 & & & 1 & & & & & 1 & & & & & 2 & 0,400 \\
\hline $\mathrm{U} 5$ & & 1 & & & & & & & & & 1 & 1 & 3 & 0,600 \\
\hline U6 & & & & & & 1 & 1 & & & & & & 2 & 0,400 \\
\hline 07 & & & 1 & & & & & & 1 & & 1 & & 3 & 0,600 \\
\hline U8 & 1 & & & & 1 & & & & 1 & & & & 3 & 0,600 \\
\hline U9 & & & & 1 & & & 1 & & & & & & 2 & 0,400 \\
\hline U10 & & 1 & & & & & 1 & & & & 1 & & 3 & 0,600 \\
\hline U11 & & & & 1 & & 1 & & & & & & & 2 & 0,400 \\
\hline$\overline{012}$ & & 1 & & 1 & & & & & & 1 & 1 & 1 & 5 & 1,000 \\
\hline U13 & & & 1 & & & 1 & & & & & & & 2 & 0,400 \\
\hline U14 & & 1 & & & & & & & & 1 & & & 2 & 0,400 \\
\hline U15 & & & & & & & 1 & 1 & & & & & 2 & 0,400 \\
\hline U16 & 1 & & & & & & & & & 1 & 1 & & 3 & 0,600 \\
\hline U17 & & 1 & & & 1 & 1 & & & 1 & & & & 4 & 0,800 \\
\hline U18 & & & & & & 1 & 1 & & & & 1 & 1 & 4 & 0,800 \\
\hline U19 & & & & 1 & & & & & & & & & 1 & 0,200 \\
\hline U20 & & 1 & & & & & & & & 1 & & & 2 & 0,400 \\
\hline U21 & & 1 & & & & & & & & & 1 & & 2 & 0,400 \\
\hline $\mathrm{U} / 22$ & & & & 1 & & 1 & & & & & & & 2 & 0,400 \\
\hline $\mathrm{U} 23$ & & & & & & & & & 1 & & 1 & & 2 & 0,400 \\
\hline U24 & & 1 & & & & 1 & & & 1 & & & & 3) & 0,600 \\
\hline $\mathrm{U} 25$ & & & 1 & & & & & & & & 1 & & 2 & 0,400 \\
\hline U26 & & & & 1 & & & & 1 & & & & & 2 & 0,400 \\
\hline $\mathrm{U} 27$ & & 1 & & & & & & & & & 1 & & 2 & 0,400 \\
\hline U28 & & 1 & 1 & & & & 1 & & & & & & 3 & 0,600 \\
\hline U29 & & & & & & & & & & 1 & 1 & & 2 & 0,400 \\
\hline U30 & & 1 & & & & 1 & & & & & & 1 & 3 & 0,600 \\
\hline ObsFreg & 3 & 12 & 5 & 7 & 3 & 9 & 6 & 3 & 6 & 6 & 12 & 4 & & \\
\hline ObsPop & 0,250 & 1,000 & 0,417 & 0,583 & 0,250 & 0,750 & 0,500 & 0,250 & 0,500 & 0,500 & 1,000 & 0,333 & & \\
\hline
\end{tabular}

Figure 10. Signature for POI4 (Gardens of Molosiglio)

- POI1 Subterranean Naples: \{wonderful, uncomfortable, worthful\}

- POI2 Church of Santa Maria Francesca: \{criminal, beautiful, noise, dangerous, emotional\}

- POI3 Piazza Plebiscito: $\{$ wonderful $\}$

- POI4 Gardens of Molosiglio: \{wonderful, abusive, vagabonds\}

By using $\alpha$-cut $>0.3$, other observations are added to the four bags:

- POI1 Subterranean Naples: \{wonderful, uncomfortable, worthful, suggestive, charming

- POI2 Church of Santa Maria Francesca: \{criminal, beautiful, noise, dangerous, emotional, amazing

- POI3 Piazza Plebiscito: \{wonderful, dirty

- POI4 Gardens of Molosiglio: \{wonderful, abusive, vagabonds, dirty, suggestive, worthful, charming\}
The Collective Perception Identifier module (CPI) computes the arithmetic mean of the sentiment scores of all the observations for a same POI, with the two different values of $\alpha$-cut. Such average values of the sentiment scores become the input of the Fuzzy Inference System for computing the collective perception. The values of the collective perception of the four POIs are reported in table 5.

Table 5. Collective perception of the four POIs with $\alpha$-cut $>0.5$ and $\alpha$-cut $>0.3$

\begin{tabular}{|l|c|c|}
\hline \multicolumn{1}{|c|}{ POI } & $\begin{array}{c}\text { CP } \\
\alpha \text {-cut }>0.5\end{array}$ & $\begin{array}{c}\text { CP } \\
\alpha \text {-cut }>0.3\end{array}$ \\
\hline Subterranean Naples & 0.69 & 0.72 \\
\hline Church & 0.36 & 0.47 \\
\hline Piazza Plebiscito & 0.83 & 0.63 \\
\hline Gardens Molosiglio & 0.33 & 0.5 \\
\hline
\end{tabular}

By analyzing the obtained results, it becomes clear that the most attractive POIs (Subterranean Naples and Piazza Plebiscito) are positively perceived by the community, confirming that they are two of the most important touristic attractions in Naples. On the other hand, the perception on the Church is really poor, and this is mainly due to the presence of observations like "criminal" and "dan- 
gerous". This is because the Church lies in a neighborhood of the city that is considered dangerous due to frequent robberies. With respect to Piazza Plebiscito (POI3), it is possible to notice a decrease in the $\mathrm{CP}$ when considering $\alpha$-cut $>0.3$. In this case, in fact, observations like "dirty" contribute to a bad perception of the area and refer to a situation of dirt and disorder that some users of the community begin to perceive in a negative way. This shows that it is useful to evaluate the collective perception at different values of $\alpha$-cut in order to identify hidden issues in the analyzed area.

\subsubsection{Area Signature and Fuzzy Cognitive Map}

The Area Signature is useful for evaluating the collective perception (CP) of the whole area and it can be used in what-if analysis scenarios based on Fuzzy Cognitive Maps. The Area Signature for the selected area of Naples downtown is evaluated by using the Eq. 11. An arithmetic mean is used as the average function. The collective perception of the whole area with $\alpha$-cut $>0.5$ is $C P=0.64$, whereas with $\alpha$-cut $>0.3$ is $C P=0.5$.

Figure 11 shows the FCM used for the what-if analysis. This map is built by integrating the maps proposed in [14] and [23] but we consider only a subsets of concepts from both maps. It contains the causal relationships between some important concepts and assets related to the management of a city, like environment, transportation, social assets and government. Indeed, the definition of a cognitive map for studying the cause-effect relationships among the different assets of a city is out of the scope of this article and it is a rather difficult task to carry out. Instead, the authors' purpose in this work is to underline the usefulness of a quantitative evaluation of the collective perception of a community for carrying out a what-if scenario analysis. Thus, the choice was made to use already existing maps for experimenting the proposed approach in this scenario. The first map used to define the map for this scenario is proposed in [14] and it is a Fuzzy Cognitive Map related to the city of Bilbao. Its main purpose is to study the effect of different plausible policy scenarios with respect to the urban resilience in the city of Bilbao, especially for the energy perspective. The approach for defining this map is interesting as it proposes to use different perspectives from multiple stakeholders and then it proposes a process to integrate all the perspectives in a single map. The second work used in order to define the FCM for the evaluation scenario is defined in [23]. This map is related to the city of Taipei City and its main focus is the relationship between different transportation strategies and several key performance indicators (like energy consumption, air pollution, infrastructure). Then, an approach similar to the one of [14] was used to aggregate the main concepts of these two maps, thus producing the map of Figure 11, which is useful to demonstrate the added value of $\mathrm{CP}$ in analyzing the quality of an urban space.

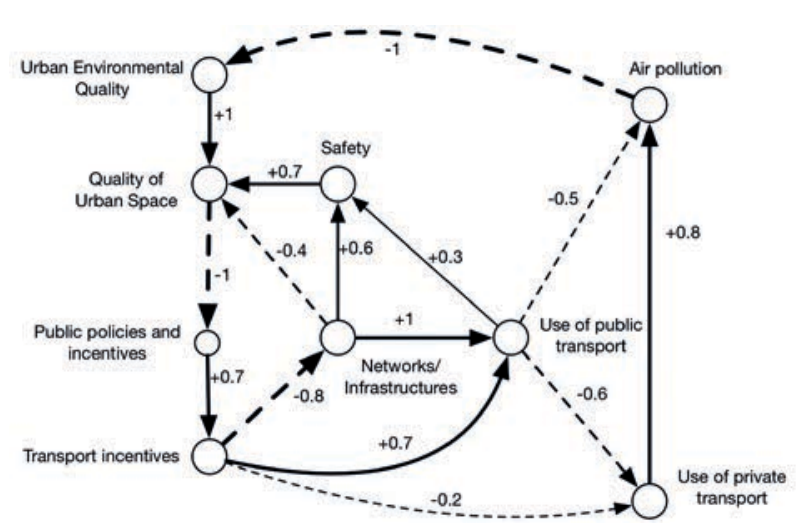

Figure 11. Fuzzy Cognitive Map for the evaluation scenario (from [10])

In the proposed map, the $\mathrm{CP}$ of the area is used as the activation level of the "Quality of Urban Space" concept. This is motivated by the fact that the Quality of Urban Space is a faceted concept which includes aspects such as quality of buildings, cultural and tourist attractions, safety, transportations and so on. For the objective of this evaluation scenario, only one indicator for the Quality of Urban Space is considered, i.e. the quality of tourist attractions, specifically of the four considered POIs. It is reasonable to state that very positive perception of urban areas match with higher levels of Quality of Urban Space.

In order to evaluate the impact of the collective perception on the concepts of the FCM, a baseline scenario with which to compare the obtained results is needed. Therefore, the equilibrium states of the map is chosen as a baseline scenario. The activation levels of the concepts of the map at the equilibrium are reported in Figure 12 and 13 in the Scenario_1 column. 
Considering the value of $C P=0.64$, and using it as Quality of Urban Space, the activation levels of the map change as reported in column Scenario_2 in Figure 12. It can be noticed that, in order to face a decrease in the value of the Quality of Urban Space (from 0.657 given by the equilibrium state to 0.64 given by the collective perception), an increase in the public policies of $0.85 \%$ is required. Thus, the FCM can help the decision makers understand which asset, among the main assets of the city, they need to intervene on for responding to a slight decrease of the collective perception regarding the quality of the urban space.

When using $\alpha$-cut $>0.3$, the value of $C P=0.5$ is used as the activation level of the FCM. Figure 13 reports the activation levels in this case with respect to the equilibrium state of the map. Here, the significant decrease of the Quality of Urban Space requires a greater improvement of the public policies (about $10.58 \%$ ). Besides, also the transportation might need some interventions (1.11\%).

\section{Discussion}

\subsection{Theoretical Implications}

This work proposes the adoption of a new decisional paradigm which is complementary to the traditional decisional approaches used in urban planning and government. Indeed, even if the traditional approaches use the opinions of experts, they rarely consider the perception that the citizens have of an entire area, and even more rarely the impact that it may have on the different assets of the city, like public policies, safety and transportation. The ultimate purpose of the proposed environment is to increase the awareness of decision makers related to the perception that a community has about a specific area of interest in the city. Such an awareness becomes systematic in the decisional processes for urban planning and development. Moreover, this environment allows to consider the opinions and the points of view of citizens and communities in a way that is less invasive as possible, since it considers observations and comments that the users have published for a completely different purpose. Consequently, it reduces the difficulty in the realization of decision support systems that need to involve a community.

\subsection{Managerial Implications}

The proposed environment supports different stakeholders in taking decisions with systems that are easily to configure and use. Its approach allows users to set different parameters to fine-tune the process, thus providing a high level of flexibility in the decision analysis. In fact, it is possible to analyze the same data at different levels of granularity, by considering less or more numbers of POIs and observations. Specifically, the alpha-cut value can be considered as a tool for the decision maker to understand what happens to the collective perception (or to the other assets of the city) when considering or eliminating some observations. This enables decision makers to easily uncover hidden observations and critical aspects that may help improve their awareness with respect to specific issues of the city, whereas with other approaches based on sentiment analysis techniques a similar result is not so easy to obtain.

Another degree of freedom is given by the linguistic quantifier used in the evaluation of the Area Signature. The decision maker may choose to weigh in different ways the positive or the negative observations, or to give a different importance to the most recent observations with respect to older observations.

\section{Conclusion}

In this work, an environment for helping decision makers within the context of a Smart City has been introduced. This environment implemented a methodology meant to acquire and exploit the collective perception of Points of Interest in a Smart City, based on an innovative combination of techniques, including semantic knowledge discovery, sentiment analysis, Fuzzy Cognitive Maps and POI signatures, which is unprecedented in this domain. As such, this methodology exploits the concepts of shared perception and awareness, enabling decision makers to take into account the different, often heterogeneous, perspectives of a wide range of stakeholders (citizens included) with respect to relevant city events and phenomena and to the city as a whole. A significant application of this process is testified by the reported experimentation of the proposed environment, carried out against a massive user community discussing the large metropolitan 


\begin{tabular}{llrrrr}
\hline & Concept & Scenario_1 & Scenario_2 & Difference & Percent_change \\
\hline 1 & Urban Environmental Quality & 0.38021 & 0.38021 & 0.00000 & 0.00082 \\
2 & Air Pollution & 0.48866 & 0.48864 & -0.00001 & -0.00270 \\
3 & Quality of Urban Space & 0.65701 & 0.64400 & -0.01301 & -1.97949 \\
4 & Safety & 0.60820 & 0.60819 & -0.00001 & -0.00161 \\
5 & Use of public Transport & 0.68602 & 0.68607 & 0.00006 & 0.00809 \\
6 & Use of private Transport & 0.37203 & 0.37200 & -0.00003 & -0.00844 \\
7 & Public Policies & 0.34141 & 0.34434 & 0.00293 & 0.85828 \\
8 & Network and Infrastructure & 0.38994 & 0.38984 & -0.00010 & -0.02467 \\
9 & Transport Incentives & 0.55946 & 0.55997 & 0.00051 & 0.09035 \\
\hline
\end{tabular}

Figure 12. Comparison between the two scenarios (equilibrium and $C P=0.64$ with $\alpha$-cut $>0.5$ )

\begin{tabular}{llrrrr}
\hline & Concept & Scenario_1 & Scenario_2 & Difference & Percent_change \\
\hline 1 & Urban Environmental Quality & 0.38021 & 0.38025 & 0.00004 & 0.01008 \\
2 & Air Pollution & 0.48866 & 0.48849 & -0.00016 & -0.03327 \\
3 & Quality of Urban Space & 0.65701 & 0.50000 & -0.15701 & -23.89712 \\
4 & Safety & 0.60820 & 0.60808 & -0.00012 & -0.01980 \\
5 & Use of public Transport & 0.68602 & 0.68670 & 0.00068 & 0.09956 \\
6 & Use of private Transport & 0.37203 & 0.37165 & -0.00039 & -0.10387 \\
7 & Public Policies & 0.34141 & 0.37754 & 0.03613 & 10.58193 \\
8 & Network and Infrastructure & 0.38994 & 0.38875 & -0.00118 & -0.30356 \\
9 & Transport Incentives & 0.55946 & 0.56569 & 0.00622 & 1.11237 \\
\hline
\end{tabular}

Figure 13. Comparison between the two scenarios (equilibrium and $C P=0.50$ with $\alpha$-cut $>0.3$ )

city of Naples, Italy. Results yielded in similar contexts may prove significantly useful for providing decision makers with a clearer awareness of the positive and/or critical aspects of urban areas, thus helping them find or refine the measures to be taken for better managing the city itself and boost its development.

Further refinements of the methodology implemented and of the environment itself include the extension of the POI knowledge base according to the availability of public touristic repositories of information related to city attractions and points of interest. Also, additional experimentations against other urban contexts and cities, as well as with respect to different concepts aside from the quality of urban space, are expected to be carried out in order to further extend the conclusions of this work and strengthen the effectiveness of the proposed environment.

\section{References}

[1] F. Antunes and J. Costa, Integrating decision support and social networks, Advances in Human-Computer Interaction, vol. 2012, no. 574276, 2012.

[2] Smarter Cities - New cognitive approaches to long-standing challenges, http://www.ibm. com/smarterplanet/us/en/smarter_cities/

overview/, accessed: 2017-02-10.

[3] D. Doran, K. Severin, S. Gokhale, and A. Dagnino, Social media enabled human sensing for smart cities, AI Communications, vol. 29, no. 1, pp. 57$75,2016$.

[4] G. P. Hancke, G. P. Hancke Jr et al., The role of advanced sensing in smart cities, Sensors, vol. 13, no. 1, pp. 393-425, 2012.

[5] G. R. Ceballos and V. M. Larios, A model to promote citizen driven government in a smart city: Use case at gdl smart city, in 2016 IEEE International Smart Cities Conference (ISC2), pp. 1-6, 2016.

[6] P. Zeile, B. Resch, L. Dörrzapf, J.-P. Exner, G. Sagl, A. Summa, and M. Sudmanns, Urban emotions-tools of integrating people perception into urban planning, in REAL CORP 2015. PLAN TOGETHER-RIGHT NOW-OVERALL. From Vision to Reality for Vibrant Cities and Regions. Proceedings of 20th International Conference on Urban Planning, Regional Development and Information Society. CORP-Competence Center of Urban and Regional Planning, pp. 905-912, 2015.

[7] A. Vakali, D. Chatzakou, V. A. Koutsonikola, and G. Andreadis, Social data sentiment analysis in smart environments-extending dual polarities for crowd pulse capturing. in DATA, pp. 175-182, 2013. 
[8] D. Toti and M. Rinelli, On the road to speed-reading and fast learning with CONCEPTUM, in Proceedings - 2016 International Conference on Intelligent Networking and Collaborative Systems, IEEE INCoS 2016, pp. 1-6, 2016.

[9] S. Baccianella, A. Esuli, and F. Sebastiani, SentiWordNet 3.0: An Enhanced Lexical Resource for Sentiment Analysis and Opinion Mining, in Proceedings of the Seventh Conference on International Language Resources and Evaluation (LREC'10). Valletta, Malta: European Language Resources Association (ELRA), 2010.

[10] G. D’Aniello, A. Gaeta, M. Gaeta, V. Loia, and M. Reformat, Collective awareness in Smart City with Fuzzy Cognitive Maps and Fuzzy sets, in 2016 IEEE International Conference on Fuzzy Systems (FUZZ-IEEE), 2016.

[11] R. R. Yager and M. Z. Reformat, Looking for likeminded individuals in social networks using tagging and e fuzzy sets, Fuzzy Systems, IEEE Transactions on, vol. 21, no. 4, pp. 672-687, 2013.

[12] B. Kosko, Fuzzy cognitive maps, International journal of man-machine studies, vol. 24, no. 1, pp. 65-75, 1986.

[13] G. D’Aniello, V. Loia, and F. Orciuoli, A multiagent fuzzy consensus model in a situation awareness framework, Applied Soft Computing, vol. 30, pp. $430-440,2015$.

[14] M. Olazabal and U. Pascual, Use of fuzzy cognitive maps to study urban resilience and transformation, Environmental Innovation and Societal Transitions, 2015 .

[15] U. Özesmi and S. L. Özesmi, Ecological models based on peoples knowledge: a multi-step fuzzy cognitive mapping approach, Ecological Modelling, vol. 176, no. 1, pp. 43-64, 2004.

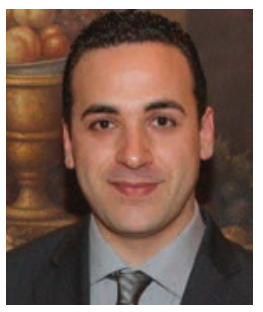

Giuseppe D'Aniello received a M.Sc. in Computer Engineering from the University of Salerno in 2013. He is currently a Ph.D. student in Information Engineering and Computer Science at the University of Salerno. He is a research scientist at the Research Consortium on Agent Systems where he has the role of project manager for the Italian R\&D project "MAR.TE". His current research interests include Situation Awareness, Semantic Web, Computational Intelligence and Granular Computing. He has coauthored several scientific papers on the aforementioned topics, which have been published on international journals and conference proceedings.
[16] F. Habib and A. Shokoohi, Classification and resolving urban problems by means of fuzzy approach, World Academy of Science, Engineering and Technology, vol. 36, pp. 894-901, 2009.

[17] D. Toti, AQUEOS: A system for question answering over semantic data, in Proceedings - 2014 International Conference on Intelligent Networking and Collaborative Systems, IEEE INCoS 2014, pp. 716719, 2014.

[18] D. Milne and I. H. Witten, An open-source toolkit for mining wikipedia, Artif. Intell., vol. 194, pp. 222-239, Jan. 2013. [Online]. Available: http:// dx.doi.org/10.1016/j.artint.2012.06.007

[19] N. Capuano, C. De Maio, S. Salerno, and D. Toti, A methodology based on commonsense knowledge and ontologies for the automatic classification of legal cases, in ACM International Conference Proceeding Series, 2014.

[20] N. Capuano, A. Longhi, S. Salerno, and D. Toti, Ontology-driven generation of training paths in the legal domain, International Journal of Emerging Technologies in Learning, vol. 10, no. 7, pp. 14-22, 2015.

[21] V. Basile and M. Nissim, Sentiment analysis on Italian tweets, in Proceedings of the 4th Workshop on Computational Approaches to Subjectivity, Sentiment and Social Media Analysis. Atlanta, Georgia: Association for Computational Linguistics, pp. 100-107, 2013. [Online]. Available: http://www. aclweb.org/anthology/w13-1614

[22] R. R. Yager, On ordered weighted averaging aggregation operators in multicriteria decisionmaking, Systems, Man and Cybernetics, IEEE Transactions on, vol. 18, no. 1, pp. 183-190, 1988.

[23] T.-A. Shiau and J.-S. Liu, Developing an indicator system for local governments to evaluate transport sustainability strategies, Ecological Indicators, vol. 34, pp. $361-371,2013$.

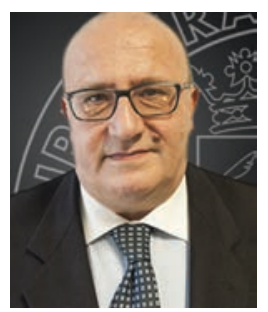

Matteo Gaeta is an Associate Professor of Information Processing Systems at the University of Salerno. His research interests involve complex information systems, Decision Support Systems, knowledge representation and management systems and Computational Intelligence. He has authored over 200 research papers published on journals, proceedings and books and he has planned and designed over 30 information systems. He is a Senior Member of IEEE and also member of the editorial board of international journals and program committees of many conferences. He is Scientific Coordinator and Manager of several International Research Projects. 


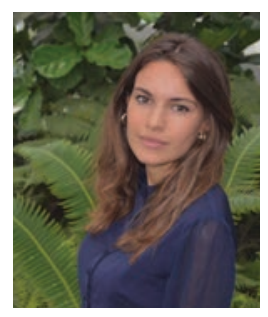

Francesca Loia is a Ph.D. student in the Department of Management at University "La Sapienza" of Rome. Her research interests include application of information technologies, resources management, service science and viable system approach. Francesca holds a M.Sc. in Industrial Management cum laude from the University of Salerno, where she conducted research on a methodology for acquiring and exploiting the collective perception of POIs in a Smart City. She received a B.Sc. in Industrial Management from the University of Salerno in 2014, carrying out a study on an energy management system for Smart Houses.

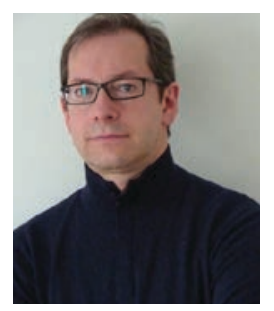

Marek Z. Reformat received his M.Sc. (with honors) from Technical University of Poznan, Poland, and his Ph.D. from University of Manitoba, Canada. He is a professor with the Department of Electrical and Computer Engineering, University of Alberta. The goal of his research is to develop methods and techniques for intelligent data modeling and analysis. Dr. Reformat is a past president of the North American Fuzzy Information Processing Society, and a presidentelect of the International Fuzzy Systems Association. He has been a member of program committees of many international conferences in Computational Intelligence and Software Engineering.

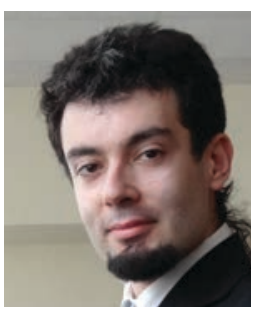

Daniele Toti holds a Ph.D. in Computer Science and Engineering and a M.Sc. and B.Sc. with honors in Computer Engineering awarded by Roma Tre University. He is currently a Senior Research Scientist at the Theoretical Biology and Bioinformatics Laboratory of Roma Tre University and a Professor at Niccolo Cusano University. His core research areas are Information Extraction and Knowledge Discovery, with relevant applications to the corporate, legal and bio-science domains. He is author of several papers in international journals and conference proceedings, is a member of ACM, IEEE and ISCB, and is an Oracle and Sun Certified Professional. 